\title{
Monochloropropanediol and glycidyl esters in infant formula and baby food products on the Danish market: Occurrence and preliminary risk assessment
}

\author{
Nguyen, Khanh Hoang; Fromberg, Arvid
}

\section{Published in:}

Food Control

Link to article, DOI:

10.1016/j.foodcont.2019.106980

Publication date:

2020

Document Version

Peer reviewed version

Link back to DTU Orbit

Citation (APA):

Nguyen, K. H., \& Fromberg, A. (2020). Monochloropropanediol and glycidyl esters in infant formula and baby food products on the Danish market: Occurrence and preliminary risk assessment. Food Control, 110, [106980]. https://doi.org/10.1016/j.foodcont.2019.106980

\section{General rights}

Copyright and moral rights for the publications made accessible in the public portal are retained by the authors and/or other copyright owners and it is a condition of accessing publications that users recognise and abide by the legal requirements associated with these rights.

- Users may download and print one copy of any publication from the public portal for the purpose of private study or research.

- You may not further distribute the material or use it for any profit-making activity or commercial gain

- You may freely distribute the URL identifying the publication in the public portal 
1 Monochloropropanediol and glycidyl esters in infant formulae and baby food products

2 on the Danish market: Occurrence and preliminary risk assessment

3

4 Khanh Hoang NGUYEN*, Arvid FROMBERG

$5 \quad$ National Food Institute, Technical University of Denmark, 2800 Kgs. Lyngby, Denmark

$6 \quad *$ Corresponding author: khng@food.dtu.dk 


\section{Abstract}

8 A GC/MS-MS method for determination of monochloropropanediol (MCPDEs) and glycidol

9 (GEs) was developed, validated, and applied to analyze $\underline{6051}$ infant formula and baby food 10 products commercially available on the Danish market. The contaminants were quantifiable 11 in almost all sample categories with the exception of fruit or vegetable based purees. The 12 highest concentrations of 3-MCPDEs and 2-MCPDEs were found in a baby biscuit product at $13 \quad 102.6 \mu \mathrm{g} / \mathrm{kg}$ and $52.8 \mu \mathrm{g} / \mathrm{kg}$, respectively. Meanwhile, a baby puff item contained GEs as 14 high as $149 \mu \mathrm{g} / \mathrm{kg}$. MCPDEs and GEs concentrations are well correlated with each others in 15 all sample types except puffs and biscuits. Occurrence data suggested that GEs formation 16 might have taken place during production of baby puffs by unknown mechanisms.

17 Preliminary exposure and risk assessment showed no apparent risk of Danish infants to these

18 chemicals in formulae and baby foods. However, special attention should be paid when

19 feeding babies with puffs or similar items due to their relatively high level of GEs.

\section{Keywords}

21 MCPD esters, glycidyl esters, infant formulae, baby food, processing contaminants, risk 


\section{Introduction}

Process contaminants are chemicals that are generated when food constituents undergo chemicals changes during processing. Some of their prime examples are the wellstudied acrylamide, polyaromatic hydrocarbons, or furan and furan derivatives ${ }^{1-3}$. Fatty acid esters of monochloropropanediol (MCPDEs) and glycidol (GEs) are emerging process contaminants that are often found in oil-containing products ${ }^{4}$. According to the position of chlorine, MCPDEs are divided into two types: 3-monochloro-1,2-propanediol esters (3MCPDEs) and 2-monochloro-1,3-propanediol esters (2-MCPDEs). The presence of 3MCPDEs in some foodstuffs was firstly reported in $2004^{5}$. This isomer of MCPDEs then came into attention in 2006 after it was detected at up to $2462 \mu \mathrm{g} / \mathrm{kg}$ in refined seed and olive oils ${ }^{6}$. Both 2- and 3-MPCDEs are formed by reactions of lipids and chlorines at high temperature, most notably during oil deodorization process (Cao et al., 2019). Under the same condition, lipids can also transform into GEs by different mechanisms than MCPDEs (Cheng et al., 2016). In many countries, MCPDEs and GEs have been detected in refined vegetable oils and products contains refined vegetable oils such as shortenings, infant formulae, bakeries, confectionaries, etc. in many countries ${ }^{9-12}$. Recent studies found very high concentrations of these contaminants in refined vegetable oils, up to $3770 \mu \mathrm{g} / \mathrm{kg}$ for 3 MCPDEs, $1910 \mu \mathrm{g} / \mathrm{kg}$ for 2-MCPDEs, and $1880 \mu \mathrm{g} / \mathrm{kg}$ for GEs ${ }^{13}$. Similarly, up to 510 and $720 \mu \mathrm{g} / \mathrm{kg}$ for 3-MCPDEs and GEs have been detected in Brazilian infant formulaeformula, respectively ${ }^{11}$. Significant levels of GEs can also be generated during heat treatment of meat patties, especially at high temperature using on open fire charcoal grill ${ }^{14}$.

Upon consumption, 2-MCPDEs, 3-MCPDEs, and GEs are readily hydrolyzed by the gastrointestinal tract into their corresponding free forms (2-MCPD, 3-MCPD, and glycidol, respectively $)^{15,16}$. This is of high concern due to their potential toxicological effects on humans. Glycidol is classified as a genotoxic carcinogen by both EFSA ${ }^{17}$ and the 
International Agency for Research on Cancer - IARC ${ }^{18}$-while 3-MCPD is listed as a non-

49 genotoxic carcinogen by IARC ${ }^{19}$. Currently very limited toxicological data of free 2-MCPD or 2-MCPDEs isare available. A recent in vivo research suggested that 2-MCPD exerts mild toxicity on rat kidney via different molecular mechanisms than 3-MCPD ${ }^{20}$.

Ubiquitous in food products with high toxicity, 3-MCPDEs and GEs have drawn a global concerns. In a scientific report in 2016 by EFSA, infants receiving only formulaeformula were estimated to be at high risks of exposure to 3-MCPD (total of free and bound forms) and glycidol (from GEs) ${ }^{17}$. Specifically, estimated daily exposure of such infants based on mean consumption and mean occurrence were $2.4 \mu \mathrm{g} / \mathrm{kg}$ b.w for 3-MCPD and $1.9 \mu \mathrm{g} / \mathrm{kg}$ b.w for glycidol. In this report, EFSA has also established a Tolerable Daily Intake (TDI) of $0.8 \mu \mathrm{g} / \mathrm{kg} \mathrm{b.w}$ for 3-MCPD but later increased it to $2 \mu \mathrm{g} / \mathrm{kg} \mathrm{b.w}$ in 2017 after some revisions ${ }^{21}$. Even higher risks have have been recently reported for infants in U.S.A 60 and Brazil ${ }^{11,22}$.

Against this background, we aim to investigate the occurrence of MCPDEs and GEs in infant formulae and baby foods available on the Danish market. From thisese occurrence data, dietary exposure and potential risks from consumption of infant formulae and baby

64 foods will be estimated.

\section{Materials and methods}

\subsection{Chemicals and standards}

Ammonium sulfate (99.5\%), diethyl ether (97\%), isooctane (99.8\%), n-hexane (99.3\%), n-heptane (99.3\%), sodium sulfate anhydrous (99\%), and sulfuric acid (95-97\%) were purchased from Merck (Darmstadt, Germany). Sodium hydrogen carbonate (99.7\%), 70 sodium bromide (99.5\%), phenylboronic acid (PBA, 97\%), and tetrahydrofuran (THF, 99.9\%) were obtained from Sigma-Aldrich Chemical (Missouri, U.S.A). Ethyl acetate 
(99.9\%), methanol $(\mathrm{MeOH}, 99.9 \%)$ and toluene (99.8\%) were provided by Rathburn Chemicals Ltd. (Walkerburn, United Kingdom). Water was obtained from a Millipore MilliQ system (Merch, Darmstadt, Germany).

Rac 1,2-bis-palmitoyl-3-chloropropanediol (PP-3-MCPD, 98\%), Rac 1,2-bispalmitoyl-3-chloropropanediol-d5 ～(PP-3-MCPD-d5， 98\%), 1,3-bis-palmitoyl-2chloropropanediol (PP-2-MCPD, 98\%), 1,3-bis-palmitoyl-2-chloropropanediol-d5 (PP-2MCPD-d5, 98\%), Glycidyl palmitate (Gly-P, 98\%), Glycidyl palmitate d5 (Gly-P-d5, 97\%) were purchased from Toronto Research Chemicals (Ontario, Canada). All stock solutions and working solutions were prepared in toluene.

\subsection{Sample collection}

A total of $\underline{6051}$ samples from different manufacturers were purchased at various supermarkets in Zealand, Denmark during the spring of 2019. The samples comprised of different commercial food products intended for infants and babies: powder infant formulae, liquid infant formulae, cereal based and vegetable based baby foods, smoothies, puffs, and biscuits. The sample details can be seen in Table 1. Samples were homogenized and stored at $-18^{\circ} \mathrm{C}$ until analysis.

\subsection{Analytical method}

The analytical method was developed and validated based on the European Commission's Joint Research Center method report EUR $27288^{23}$, and AOCS Official First Action Method $2018.03^{24}$ with some modifications.

\subsubsection{Sample preparation}

Since MCPDEs and GEs are highly lipophilic, a fat extraction step was necessary to extract these contaminants out of food matrices. Based on the fat content information on the food packages, an amount of sample containing approximately 100-110 mg of fat was 
weighed into a $50 \mathrm{ml}$ centrifuge tube (maximum $5 \mathrm{~g}$ of sample). The sample was spiked with $50 \mu \mathrm{L}$ of an internal standard mixture (5 ng/ $\mu \mathrm{L})$ containing PP-3-MCPD-d5, PP-2-MCPD-d5, and Gly-P-d5. Then, $12 \mathrm{~mL}$ of Milli-Q water and $12 \mathrm{~mL}$ of ethyl acetate were added to the tube and the mixture was vortexed for $10 \mathrm{~s}$ before sonication for $15 \mathrm{~min}$ at $50{ }^{\circ} \mathrm{C}$ in an ultrasonicator (Branson 5510, Branson Ultrasonics, U.S.A). Afterwards, the samples were placed on a high-high-speed vertical shaker (Geno Grinder 2100, SPEX SamplePrep, U.S.A) and extracted at $1500 \mathrm{rpm}$ for $5 \mathrm{~min}$. For better phase separation and salting out effect, $10 \mathrm{~g}$ of sodium sulfate anhydrous was added before the sample was shaken again at $1500 \mathrm{rpm}$ for 3 min followeding by centrifugation at $4800 \mathrm{rpm}_{-}^{25}$. The upper layer was collected and an additionalether $12 \mathrm{~mL}$ of ethyl acetate was added to the tube for a second extraction (including ultrasonication and shaking). Extracted fat from the sample was obtained by evaporation of the combined upper layers to dryness under a nitrogen stream at $40{ }^{\circ} \mathrm{C}$.

It has been reported that food items contain a significant amount of partialglycerides,

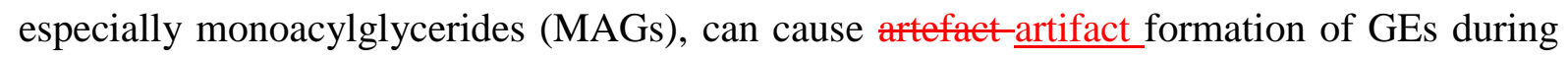
bromination of GEs ${ }^{26}$. Therefore, a cleanup step by aminopropyl SPE cartridge was employed to remove MAGs ${ }^{26}$. Extracted fat was re-dissolved in $1 \mathrm{~mL}$ of mixture A containing n-hexane and ethylacetate at a ratio of 85:15 (v/v) then loaded on a SPE cartridge previously conditioned with $2 \mathrm{~mL}$ of mixture A. The cartridge was eluted with $10 \mathrm{~mL}$ of mixture A into a collection test tube then the sample was evaporated to dryness under a nitrogen stream at $40{ }^{\circ} \mathrm{C}$.

The bromination of GEs to 3-monobromopropanediol monoesters (3-MBPDEs), transesterification, and derivatizations were performed according to Dubois et al., 2018. Brieftly, the procedure included bromination of GEs by acidic sodium bromide solution; acid methanolysis; salting out of fatty acid methyl esters by ammonium sulfate and n-heptane; extraction of free forms of 3-MCPDEs, 2-MCPDEs, and 3-MBPDEs by ethyl acetate; and 
121 derivatization by PBA. After the derivatization process, the sample was carefully evaporated to dryness under a gentle nitrogen stream at $40{ }^{\circ} \mathrm{C}$ then re-dissolved in $300 \mu \mathrm{L}$ of isooctane. While PBA is a good derivatization reagent for diols, the chemical is quite harsh and sticky on GC columns, leading to rapid column degradation. Therefore, the isooctane containing

125 derivatized analytes wasast transferred into a Mini Uni-Prep PTFE housing (Whatmann, U.S.A) and stored at $-18{ }^{\circ} \mathrm{C}$ for $1-2$ hours to precipitate excess PBA. Afterwards, the Mini Uni-Prep $0.45 \mu \mathrm{m}$ filter (PFTE media) was pressed into the housing to filter out precipitated PBA. The filtered supernatant was transferred to a GC glass vial for analysis by GC-MS/MS.

\subsubsection{Instrument analysis} MCPD, 2-MCPD, and 3-MBPD, respectively) was performed on a GC-MS/MS system

132 (Thermo Fisher Scientific, U.S.A) comprised of a Trace 1300 gas

133 ehromarographchromatography, a TSQ 8000 EVO triple quadrupole mass spectrometer, and

134 a Triplus RSH autosampler. Chromatographic separation of the target analytes was achieved 135 on a Supelco Equity-1 capillary column $(30 \mathrm{~m}$ x $0.25 \mathrm{~mm}$ i.d. $\times 1.00 \mu \mathrm{m}$ film thickness, 136 Sigma-Aldrich, Missouri, U.S.A). A $1 \mu \mathrm{L}$ aliquot of sample was injected in PTV splitless 137 mode using helium as carrier gas at a constant flow rate of $1.5 \mathrm{~mL} / \mathrm{min}$. The PTV program 138 was: $70{ }^{\circ} \mathrm{C}$ for $0.02 \mathrm{~min}$; increased to $280{ }^{\circ} \mathrm{C}$ at a rate of $8.5^{\circ} \mathrm{C} / \mathrm{s}$ for $8 \mathrm{~min}$; then increased to $139330{ }^{\circ} \mathrm{C}$ at a rate of $10{ }^{\circ} \mathrm{C} / \mathrm{s}$ for $14.5 \mathrm{~min}$. The splitless time was $0.5 \mathrm{~min}$, after that a split flow 140 of $30 \mathrm{~mL} / \mathrm{min}$ was applied. The bBackflush feature was utilized to remove residues of excess 141 PBA and reduce maintain-maintenance frequency. The following oven program was used: 142 initial temperature of $60{ }^{\circ} \mathrm{C}$ for $1 \mathrm{~min}$; increased $30{ }^{\circ} \mathrm{C} / \mathrm{min}$ to $120^{\circ} \mathrm{C}$; ramped to $250{ }^{\circ} \mathrm{C}$ at 8

$143{ }^{\circ} \mathrm{C} / \mathrm{min}$; then increased $30{ }^{\circ} \mathrm{C} / \mathrm{min}$ to $260{ }^{\circ} \mathrm{C}$, held for $3 \mathrm{~min}$, for a total run time of $22.6 \mathrm{~min}$.

144 The transfer line and ion source were held constant at $300{ }^{\circ} \mathrm{C}$ and $280{ }^{\circ} \mathrm{C}$, respectively. 
145 Detection was performed in positive electron impact ionization $(70 \mathrm{eV})$ with selected reaction 146 monitoring (SRM) mode. Detailed SRM scans are shown in Table S1.

\subsection{Method validation}

The method was validated in-house by two persons in terms of linearity, precision

149 (intra-lab reproducibility and inter-day repeatability), accuracy (recovery), limit of detection

150 (LOD), and limit of quantification (LOQ) according to the guidelines by ISO 17025.

151 Linearity was assessed using an eight point procedural calibration curve over the range of 0 -

$1521000 \mathrm{ng}$ (bound forms). Calibrants were prepared by spiking native standards (at the levels of

$1532,6,20,50,100,300,500$, and $1000 \mathrm{ng}$ ) and labeled standards ( $250 \mathrm{ng})$ into $5 \mu \mathrm{L}$ of extra

154 virgin olive oil and proceeded to bromination, transesterification, and derivatization as

155 normal samples. The linear procedural calibration curve was plotted between the peak area

156 ratio of an analyte with its corresponding internal standard on the Y-axis versus the amount

157 of that analyte on the $\mathrm{X}$-axis using $1 / \mathrm{X}$ weighting to ensure fitting across the whole

158 calibration range.

Precision and accuracy were evaluated by spiking pseudo-blank vegetable oil, infant

160 formulaeformula and baby food samples (containing low levels of MCPDEs and GEs) with

161 native standards at two concentration levels (Table 2). Each level of concentration was

162 analyzed in eight replicates (four replicates on the first day by the first technicianpersonnel and another four on the second day with a second personnetechniciant). Additionally, a reference material of vegetable oil (FAPAS T2646QC) was used to further assess the trueness

165 of analysis results for 3-MCPDEs and GEs. LODs and LOQs were calculated based on the

166 standard deviations of MCPDEs and GEs in 10 pseudo-blank replicates $\left(\operatorname{Std}_{\text {blk }}\right)$ as following:

$167 \mathrm{LOD}=3.3 \times \mathrm{Std}_{\mathrm{blk}} ; \mathrm{LOQ}=3.3 \times \mathrm{LOD}$. The pseudo-blank for each assessed matrix in Table 2 was a low-contaminated sample of the corresponding matrix. Since the method utilized an indirect analysis approach, concentrations of MCPDEs; and GEs were calculated and 
170 expressed as $\mu \mathrm{g} / \mathrm{kg}$ of free form equivalentbound MCPDs and bound glycidol for all samples 171 in this study.

\section{3. Results and discussion}

\section{3.1. Method validation}

Procedural calibration curves showed excellent linearity throughout the whole calibration range $\left(\mathrm{R}^{2}>0.9997\right)$. The calibration residual plots of MCPDEs and GEs showed a random pattern and the average standardized residual of less than $8 \%$ was observed for all

177 calibration levels (data not shown). Since there are no available performance criteria set by

178 the European Union (EU) for methods of analysis for MCPDEs and GEs, we adapted the

179 performance criteria for analysis of free 3-MCPD set by EU regulation with some

180 modifications ${ }^{27}$. Specifically, the precision has to be smaller than $15 \%$ and the recovery must

181 fall between 75 to $110 \%$ at all levels of concentration. under intra-lab reproducibility $\left(\mathrm{CV}_{\mathrm{LR}}, \%\right)$, coefficient of variation under intra-day

184 repeatability $\left(\mathrm{CV}_{\mathrm{DR}}, \%\right)$, and recovery $(\mathrm{R}, \%)$ showed very good results and met all the set

185 criteria whichas can be seen in Table 2. Briefly, the $\mathrm{CV}_{\mathrm{LR}}$ for 2-MCPDEs, 3-MCPDEs, and 186 GEs ranged from 1.1 to $7.8 \%$ while the $\mathrm{CV}_{\mathrm{DR}}$ ranged from 1.1 to $9.5 \%$. The method also 187 provided good recovery for interested analytes which ranged from 84 to $106 \%$. Analysis of 3-

188 MCPDEs and GEs in the reference vegetable oil material FAPAS T2646QC further 189 confirmed trueness of the method (Table S.2). The LOQs for 2-MCPDEs, 3-MCPDEs, and

190 GEs in baby food were 1,2 , and $1.2 \mu \mathrm{g} / \mathrm{kg}$, respectively, while those for infant 191 formulaeformula were $1.2,1$, and $0.5 \mu \mathrm{g} / \mathrm{kg}$, respectively (Table 2).

192 In consideration of the achieved linearity, precision, accuracy, LODs, and LOQs, the 193 validated method is suitable for monitoring-of 2-MCPDEs, 3-MCPDEs, and GEs in infant 
194 formulae and baby foods. The method was accredited and then applied to analyze $\underline{6051}$ infant formulaeformula and baby food samples commercially available on the Danish market.

\section{3.2. Occurrence}

Table 1 shows the levels of the processing contaminants found in infant

198 formulaeformula and baby food in Denmark together with details about each product

199 including sample type, fat content, and intended usage age. In all fruit/vegetable based

200 purees, 2-MCPDEs, 3-MCPDEs, and GEs presented at less than LOQ level with the only

201 exception of GEs in one sample at $1.7 \mu \mathrm{g} / \mathrm{kg}$. This is reasonable as these contaminants arouse

202 from exposure of fat to chloride and/or high temperature ${ }^{7,28}$ while the fat contents in

203 fruit/vegetable based puree areare minimal (less than 2\%). For cereal based purees, the three

204 chemicals showed quantification frequencies (the percentage of samples above LOQs) at

$20550 \%$ for 2-MCPDEs, $73 \%$ for 3-MCPDEs, and $41 \%$ for GEs. In these products, 2-MCPDEs and GEs presented at similar levels $(<\mathrm{LOQ}-3.8 \mu \mathrm{g} / \mathrm{kg})$ and both of their concentrations are significantly lower $(\mathrm{P}$-value $<0.001)$ than $3-\mathrm{MCPDEs}$ in the same samples $(<\mathrm{LOQ}-9.9$ $\mu \mathrm{g} / \mathrm{kg}$ ). A s Similar contaminants profile was also observed in puree powder made from cereal

209 (2-MCPDEs $\approx$ GEs < 3-MCPDEs), however with slightly higher concentrations. The higher

210 concentrations in puree powder is are likely because of their higher fat content (Table 1),

211 most of which comprised of vegetable oils such as rapeseed oil or sunflower oil. Among eight

212 analyzed puree powder samples, the contaminants were not quantifiable in only one product

213 which containeds mostly dried wholegrain rye with naturally occurring fat (2\%) and no added 214 vegetable oils.

MCPDEs and GEs have been detected in infant formulaeformula products in many

216 countries (Table 3). In this study, we found these chemicals in all test samples of infant

217 formulaeformula, both in liquid and powder form. In liquid formulaeformula, the mean concentrations of 2-MCPDEs, 3-MCPDEs, and GEs were 2.3, 5.6, and $1.1 \mu \mathrm{g} / \mathrm{kg}$, 
219 respectively, while those for powder formulaeformula were $15.5,38$, and $12.7 \mu \mathrm{g} / \mathrm{kg}$, 220 respectively. The lowest levels of MCPDEs and GEs were observed in an infant formula

221 from manufacturer $\mathrm{C}$, which were at least 3 times lower than other products. On the other 222 hand, the highest concentrations of all contaminants were detected in a product from 223 manufacturer B intended for newborn babies. While 3-MCPDEs and GEs have been 224 extensively assessed in vegetable oils, the occurrence data of MCPDEs and GEs in infant 225 formulaeformula is still somewhat limited. In comparison with previous studies, itt is clear 226 from Table 3 that the levels of these contaminants are lowest in infant formulaeformula 227 products from this study-in comparison with previous studies. This might be due to the fact 228 that the oil and food industry have been constantly working on mitigation of processing 229 contaminants including MCPDEs and GEs ${ }^{4}$.

$230 \quad$ On 26 February 2018, the European Union has-published its Regulation No 2018/290 231 (amending its Regulation No 1881/2006) to set the maximum levels of GEs in vegetable oils 232 and fats, powder/liquid infant formulaeformula and baby foods ${ }^{29}$. Specifically, the concentrations of GEs in infant formulaeformula and baby foods have to be lower than 50 $234 \mu \mathrm{g} / \mathrm{kg}$ in powder form and $6.0 \mu \mathrm{g} / \mathrm{kg}$ in liquid form. All of the analyzed infant 235 formulaeformula and purees in this study contained compliedsafe levels of GEs in accordance to-with EU regulations. Currently,-regulations for maximum levels of 2- or 3-MCPDEs are 237 not available.

238 Along with infant formulaeformula and puree products, in this study, we also assessed 239 the levels of MCPDEs and GEs in baby finger foods (biscuits or puffs) which are currently 240 not under EU regulations. These products were intended for babies over 6 months old (puffs) 241 or over 10-12 months old (biscuits). The processing contaminants were detected in eight

242 ameng of nine assessed samples. Similar to puree powder, the only puff item does not contain 243 MCPDEs and GEs comprises of only green peas (80\%) and corn (20\%) without any added 
vegetable oils. These observations further confirm the fact that the presence of MCPDEs and

245 GEs is highly associated with usage of refined vegetable oils in food processing ${ }^{4,28}$. Baby

246 biscuits contained the highest levels of MCPDEs among all studied infant formulaeformula

247 and baby food products. Specifically, 2-MCPDEs presented at the concentration range

248 between 28.6 to $52.8 \mu \mathrm{g} / \mathrm{kg}$ while the ranges for 3-MCPDEs and GEs were $59.6-102.6$

$249 \mu \mathrm{g} / \mathrm{kg}$ and $16.2-35 \mu \mathrm{g} / \mathrm{kg}$, respectively. The two biscuit products with the highest

250 concentrations of 2- and 3-MCPDEs (Table 1) contained only palm oil while the other two

251 used a mix of palm and sunflower oil. This might be the reason for their differences in

252 MCPDEs levels, as palm oil is well known for its potential to form MCPDEs and GEs during

253 refining due to its high diacylglycerides content ${ }^{7}$. Indeed, the highest levels of 3-MCPDEs

254 were found in palm oil among all analyzed vegetable oils (including sunflower oil) in a recent

255 study conducted by EFSA (EFSA CONTAM Panel, 2016). Currently, there are are limited

studiestery limited study about the occurrence of MCPDEs and GEs in baby foods rather than infant formulaeformula. Sadowska-Rociek et al. (2018) has-have found the presence of 3-MCPDEs in baby biscuits purchased in Poland during 2016-2017. In comparison with this study, 3-MCPDEs in Polish baby biscuits showed higher concentrations, ranging between 88 $-443 \mu \mathrm{g} / \mathrm{kg}$. Meanwhile, GEs was-were not detected in their samples.

Baby puffs showed similar concentrations of 2-MCPDEs and 3-MCPDEs to cereal based puree powder, ranging between <LOQ - 8.7 $\mu \mathrm{g} / \mathrm{kg}$ and $<\mathrm{LOQ}-26.5 \mu \mathrm{g} / \mathrm{kg}$,

263 respectively. Surprisingly, GEs were found at much higher levels than MCPDEs in baby 264 puffs with the average concentration of $90.7 \mu \mathrm{g} / \mathrm{kg}(27.5-149 \mu \mathrm{g} / \mathrm{kg})$. In fact, GEs 265 concentrations were the highest in these items among all assessed products in this study. 266 Apart from the green peas based puff, all other puffs comprised of mostly cornstarch (71$26775 \%$ ) and sunflower oil (13-15\%). It is unclear whether original GEs content in oil is the sole 268 contributor to the spiked level of GEs in puffs, or if puff production processes also is a 
contributing factor. Puffs are usually made by food extrusion machines where raw ingredients

270

271

272

273 are continuously mixed and fed into a heated extruder, then discharged through a confined volume opening forming puffy products. In order to properly cook the ingredients, high temperatures as highmuch as $200^{\circ} \mathrm{C}$ must be employed at the extruder ${ }^{30}$. At this temperature, GEs can form rapidly from partial acylglycerides presented in vegetable oils ${ }^{8}$.

\subsection{Correlations among MCPDEs, GEs, and fat content}

To examine the relationship between an individual contaminant with another or with fat content of the product, Spearman rank correlation was employed. Despite various type, composition, and content of vegetable oils in infant formulaeformula and baby foods from different manufacturers, Spearman rank correlation test revealed that all three contaminants are greatly correlated to fat content ( $p<0.001$ in all cases) (Table S.3). The test also showed high positive correlation coefficients between fat content and levels of MCPDEs and GEs, meaning the more fat in the products is, the higher concentrations of these contaminants. This is in agreement with Zelinková et al. (2009) where the concentrations of 3-MCPDEs were proportioned with fat content of infant formulaeformula in the Czech Republic. However, a recent study in infant formulaeformula in Brazil found no such correlations ${ }^{11}$.

Previous studies have proposed that, at high temperature, MCPDEs precursors such as tri-, di-, and mono-acylglycerides can undergo multiple mechanisms to form both 2-MCPDEs and 3-MCPDEs at the same time, albeit at different ratio ${ }^{32,33}$. It is therefore hypothesized that the two isomers co-present in contaminated samples. As expected, significant correlation between 2-MCPDEs and 3-MCPDEs was found at very high degree $(p<0.001$, Spearman rank's correlation coefficient $=0.972)$. Regression analysis also detected a strong linear relationship between the concentrations of 2- and 3-MCPDEs in this study (adjusted $\mathrm{R}^{2}=$ 0.99) (Figure 1). Similar A similar finding was reported previously in infant formulaeformula ${ }^{34}$. The concentration ratios between 2- and 3-MPCDEs in quantifiable samples from our 
294 study mostly ranged from 0.31 to 0.51 with a median of 0.39 (Table 1 ). Others found 295 comparable ratio 2- to 3-MCPDEs in infant formulaeformula from different countries: 0.45 in

296 Germany ${ }^{34}$ and 0.38 in Canada ${ }^{35}$. These ratios are also in good agreement with values found 297 in different vegetable oils such as palm, coconut, corn, or peanut oil ${ }^{36,37}$. Assessment of 298 MCPDEs isomerization model on crude palm oil confirmed the direct relation of 2- to 3299 MCPDEs ratio with deodorization temperature ${ }^{38}$. At $180^{\circ} \mathrm{C}$, the 2- to 3-MCPDEs ratio in 300 refined palm oil was about 0.13 , increased to 0.29 at $220^{\circ} \mathrm{C}$ and reach equilibrium of 0.5 at $301240-260{ }^{\circ} \mathrm{C}$ deodorization temperature ${ }^{38}$. Low deodorization temperature is also an industrial 302 approach to reduce the final levels of MCPDEs and GEs in refined vegetable oils ${ }^{4}$. In this 303 survey, the only product showed 2- to 3-MCPDEs ratio out of the 0.31-051 range was a 304 powder formulae produced by manufacturer $\mathrm{C}$ (item number 46, Table 1 ) at the ratio of 0.15 . 305 This product contained sunflower and rapeseed oil and showed the lowest concentrations of 306 all three contaminants among the powder formulaeformula group, even at comparable levels with liquid formulaeformula samples despite having much higher fat content (Table 1). It also

308 has the lowest concentrations of MCPDEs and GEs on fat basis among all quantifiable 309 samples in this study (data not shown). This is an indication that low temperature 310 deodorization together with other possible mitigation strategies (i.e. by using different types 311 of edible oils than palm oil) might have been applied to significantly reduce the level of 312 MCPDEs and GEs in item number 46.

313 Despite the significant correlation between GEs and the two MCPDEs isomers in the 314 samples, no linear relationships could be observed by regression analysis (Figures $2 \mathrm{~A}$ and $3153 \mathrm{~A})$. Visual inspection of the scatter plots suggested biscuit and puff products might be the 316 reason for this non-linearity behavior. By removing biscuit and puff samples from regression 317 analysis models, decent linearity could be detected with $\mathrm{R}^{2} \approx 0.85$ between the content of 318 GEs and either 2-MCPDEs or 3-MCPDEs (Figures 2B and 3B). Interestingly enough, the 
relationship between MCPDEs and GEs in biscuits and puffs products are opposite to each other. In biscuits, the higher MCPDEs concentration is, the lower GEs level that product contains. On the contrary, in puff items, the amount of MCPDEs and GEs seems to be proportional to each other. This implies the production of biscuits or puffs lead to changes in concentration profiles of MCPDEs and GEs in different manners, and also different from those in infant formulaeformula and baby puree (both ready to consume and powder forms). More studies are therefore needed to investigate the formation of MCPDEs and GEs in snacks such as biscuits or puffs, especially those intended for babies.

\subsection{Preliminary exposure estimation and risk assessment}

328 The Danish Health Authority recommended that an infant should be over 4 months old before starting on solid foods, however, it is best to wait until the child is 6 months of age ${ }^{39}$. Since there is no available data on baby food consumption after 6 months, we estimated the exposure and risk for 0-5 months babies who receive formulaeformula only. In consideration of neither TDI nor MOE threshold for 2-MCPDEs was established, only the risk assessment of 3-MCPDEs and GEs were discussed.

The Danish Health Authority suggested $170 \mathrm{ml} / \mathrm{kg}$ bodyweight (b.w) of formulaeformula per day during an infant's first month of life, then slowly decreased to 110 $336 \mathrm{ml} / \mathrm{kg}$ b.w for $1-5$ months infants ${ }^{40}$. Therefore, we calculated the MCPDEs and GEs intake

337 for two groups of infants: 0-1 months and 2-5 months using mean concentrations of MCPDEs and GEs in formulaeformula products intended for this age group. A factor of 7.7 was used to convert powder formulaeformula into ready to use liquid formulaeformula as previously done

340 by EFSA ${ }^{17}$. The average infant body weight was $4.2 \mathrm{~kg}$ for $0-1$ months and $7.3 \mathrm{~kg}$ for $2-5$

341 months ${ }^{40}$. In this study, we assumed $100 \%$ conversion of the esters into their free forms upon 342 consumption ${ }^{17}$. The preliminary exposure assessment to 3-MCPDEs and GEs of Danish 343 infants receiving infant formulaeformula only (expressed as their corresponding free form 
equivalent) is shown in Table 4. The 2-MCPDEs daily intake was $0.3 \mu \mathrm{g} / \mathrm{kg} \mathrm{b}$.w/day for $0-1$ months and $0.19 \mu \mathrm{g} / \mathrm{kg}$ b.w/day for $2-5$ months babies. Meanwhile, 0-1 months and 2-5 months infants were exposed to 0.75 and $0.49 \mu \mathrm{g} / \mathrm{kg}$ b.w/day of 3-MCPDEs, respectively. In both age groups, the estimated 3-MCPDEs exposure values were considerably lower than the TDI of $2 \mu \mathrm{g} / \mathrm{kg}$ b.w/day published by EFSA ${ }^{21}$. The estimated 3-MCPDEs exposure for children from 0 to 5 months in this study was also the lowest in comparison with previous studies in Europe, U.S.A, ander Brazil (Table 4).

Similarly, the GEs exposure for 0-1 months and 2-5 months children were calculated at 0.23 and $0.15 \mu \mathrm{g} / \mathrm{kg}$ b.w/day, respectively. These values were 5 to 10 times lower that $\underline{\text { than }}$ those reported in other countries ${ }^{11,17,22}$. Since no TDI is currently available for GEs exposure, the margin of exposure to GEs (MoE) was calculated according to a previous study by EFSA where the T25 value of $10.2 \mathrm{mg} / \mathrm{kg}$ b.w per day for peritoneal mesothelioma in male rats were used ${ }^{17}$. A MoE smaller than 25,000 is of health concern for GEs exposure. In both assessed age groups in this study, the MoEs for GEs exposure were larger than 25,000 (data not shown). In general, our estimation indicated that under average consumption scenario using recommended daily intakes, the exposure of Danish infants to 3-MCPDEs and GEs in infant formulaeformula is considered of low health concern.

\section{Conclusion}

362 This study provided the first investigation on the occurrence of 2- and 3-MCPD esters and

363 glycidyl esters in infant formulaeformula and baby foods in Denmark. Overall, low levels of 364 MCPDEs and GEs were observed in most vegetable oil containing products while samples with no added oil showed <LOQs levels. The degree of MCPDEs and GEs contamination

366 was in the following order: cereal based puree $\approx$ liquid formulaeformula $<$ cereal based puree powder $\approx$ baby puffs $<$ powder formulaeformula $<$ baby biscuits, with the exception for GEs where baby puffs showed the highest concentrations. Industrial mitigation strategies for 
369 MCPDEs and GEs have demonstrated the effectiveness in reducing these chemicals' levels in

370 baby puree and infant formulaeformula. However, more attention should be paid on the

371 formation, and possibly also mitigation measures, of MCPDEs and GEs in baby biscuits,

372 puffs, or any other similar products where dry heating is applied. Preliminary exposure

373 estimation and risk assessment revealed that there are-is no apparent risk of exposure to 3-

374 MCPDEs and GEs from infant formulaeformula and baby foods for Danish infants.

375 Declarations of interest: none

\section{Acknowledgement}

377 The authors would like to thank Line Christoffersen for technical assistance during sample

378 preparation and Malene Høj Outzen for providing Danish Food Authority’s recommendation

379 on infant formulaeformula consumption. 


\section{References}

381 (1) Fromberg, A.; Fagt, S.; Granby, K. Furan in Heat Processed Food Products Including 382 Home Cooked Food Products and Ready- to- eat Products. EFSA Support. Publ. 2009, 6 (9), 1-49. https://doi.org/10.2903/sp.efsa.2009.EN-1.

(2) Zelinkova, Z.; Wenzl, T. The Occurrence of 16 EPA PAHs in Food - A Review. Polycycl. Aromat. Compd. 2015, 35 (2-4), 248-284. https://doi.org/10.1080/10406638.2014.918550.

(3) Granby, K.; Fagt, S. Analysis of Acrylamide in Coffee and Dietary Exposure to Acrylamide from Coffee. Anal. Chim. Acta 2004, 520 (1-2), 177-182. https://doi.org/10.1016/j.aca.2004.05.064.

(4) Oey, S. B.; van der Fels-Klerx, H. J.; Fogliano, V.; van Leeuwen, S. P. J. Mitigation Strategies for the Reduction of 2- and 3-MCPD Esters and Glycidyl Esters in the Vegetable Oil Processing Industry. Compr. Rev. Food Sci. Food Saf. 2019, 18 (2), 349-361. https://doi.org/10.1111/1541-4337.12415.

(5) Svejkovská, B.; Novotný, O.; Divinová, V.; Réblová, Z.; Doležal, M.; Velíšek, J. Esters of 3-Chloropropane-1,2-Diol in Foodstuffs. Czech J. Food Sci. 2004, 22 (No. 5), 190-196. https://doi.org/10.17221/3423-CJFS.

(6) Zelinková, Z.; Svejkovská, B.; Velíšek, M.; Doležal, M. Fatty Acid Esters of 3Chloropropane-1,2-Diol in Edible Oils. Food Addit. Contam. 2006, 23 (12), 12901298. https://doi.org/10.1080/02652030600887628.

(7) Cao, R.; Wang, S.; Li, C.; Liu, W.; Zhou, H.; Yao, Y. Molecular Reaction Mechanism 401 for the Formation of 3-Chloropropanediol Esters in Oils and Fats. J. Agric. Food Chem. 2019. https://doi.org/10.1021/acs.jafc.8b06632.

403 (8) Cheng, W.; Liu, G.; Liu, X. Formation of Glycidyl Fatty Acid Esters Both in Real 
Edible Oils during Laboratory-Scale Refining and in Chemical Model during High https://doi.org/10.1021/acs.jafc.6b01520.

407

408

409

410

411

412

413

414

415

416

417

418

419

420

421

422

423

424

425

426

427

(9) Wang, L.; Ying, Y.; Hu, Z.; Wang, T.; Shen, X.; Wu, P. Simultaneous Determination of 2- And 3-MCPD Esters in Infant Formula Milk Powder by Solid-Phase Extraction and GC-MS Analysis. J. AOAC Int. 2016, 99 (3), 786-791.

https://doi.org/10.5740/jaoacint.15-0310.

(10) Leigh, J.; MacMahon, S. Occurrence of 3-Monochloropropanediol Esters and Glycidyl Esters in Commercial Infant Formulas in the United States. Food Addit. Contam. Part A Chem. Anal. Control. Expo. Risk Assess. 2017, 34 (3), 356-370. https://doi.org/10.1080/19440049.2016.1276304.

(11) Arisseto, A. P.; Silva, W. C.; Scaranelo, G. R.; Vicente, E. 3-MCPD and Glycidyl Esters in Infant Formulas from the Brazilian Market: Occurrence and Risk Assessment. Food Control 2017, 77, 76-81. https://doi.org/10.1016/j.foodcont.2017.01.028.

(12) Sadowska-Rociek, A.; Surma, M.; Cieslik, E. Analysis of Acrylamide, 3Monochloropropane-1,2-Diol, Its Esters and Glycidyl Esters in Carbohydrate-Rich Products Available on the Polish Market. Rocz. Panstw. Zakl. Hig. 2018, 69 (2), 127137.

(13) Kamikata, K.; Vicente, E.; Arisseto-Bragotto, A. P.; Miguel, A. M. R. de O.; Milani, R. F.; Tfouni, S. A. V. Occurrence of 3-MCPD, 2-MCPD and Glycidyl Esters in Extra Virgin Olive Oils, Olive Oils and Oil Blends and Correlation with Identity and Quality Parameters. Food Control 2019, 95 (June 2018), 135-141. https://doi.org/10.1016/j.foodcont.2018.07.051. 
(14) Inagaki, R.; Hirai, C. Formation of Glycidol Fatty Acid Esters in Meat Samples Cooked by Various Methods. J. Food Process. Technol. 2016, 07 (02), 2-7. https://doi.org/10.4172/2157-7110.1000557.

(15) Abraham, K.; Appel, K. E.; Berger-Preiss, E.; Apel, E.; Gerling, S.; Mielke, H.; Creutzenberg, O.; Lampen, A. Relative Oral Bioavailability of 3-MCPD from 3MCPD Fatty Acid Esters in Rats. Arch. Toxicol. 2013, 87 (4), 649-659. https://doi.org/10.1007/s00204-012-0970-8.

(16) Appel, K. E.; Abraham, K.; Berger-Preiss, E.; Hansen, T.; Apel, E.; Schuchardt, S.; Vogt, C.; Bakhiya, N.; Creutzenberg, O.; Lampen, A. Relative Oral Bioavailability of Glycidol from Glycidyl Fatty Acid Esters in Rats. Arch. Toxicol. 2013, 87 (9), 16491659. https://doi.org/10.1007/s00204-013-1061-1.

(17) EFSA CONTAM Panel. Risks for Human Health Related to the Presence of 3- and 2- monochloropropanediol (MCPD), and Their Fatty Acid Esters, and Glycidyl Fatty Acid Esters in Food. EFSA J. 2016, 14 (5). https://doi.org/10.2903/j.efsa.2016.4426.

(18) IARC. Glycidol. IARC Monogr. 2000, 1-18.

(19) IARC. 3-Monochloro-1,2-Propanediol. IARC Monogr. 2013, 101.

(20) Frenzel, F.; Oberemm, A.; Braeuning, A.; Lampen, A. Proteomic Analysis of 2Monochloropropanediol (2-MCPD) and 2-MCPD Dipalmitate Toxicity in Rat Kidney and Liver in a 28-Days Study. Food Chem. Toxicol. 2018, 121 (August), 1-10. https://doi.org/10.1016/j.fct.2018.08.013.

(21) EFSA CONTAM Panel. Update of the Risk Assessment on 3- monochloropropane Diol and Its Fatty Acid Esters. EFSA J. 2018, 16 (1), 1-48. https://doi.org/10.2903/j.efsa.2018.5083.

(22) Spungen, J. H.; MacMahon, S.; Leigh, J.; Flannery, B.; Kim, G.; Chirtel, S.; Smegal, 
(23) Wenzl, T.; Samaras, V.; Giri, A.; Buttinger, G.; Karasek, L.; Zelinkova, Z.

Development and Validation of Analytical Methods for the Analysis of 3- MCPD

(Both in Free and Ester Form) and Glycidyl Esters in Various Food Matrices and Performance of an Ad- hoc Survey on Specific Food Groups in Support to a Scientific Opinion on Compre. Publ. Off. Eur. Union 2015. https://doi.org/10.2787/82118.

(24) Dubois, M.; Empl, A.-M.; Jaudzems, G.; Basle, Q.; Konings, E. Determination of 2and 3-MCPD as Well as 2- and 3-MCPD Esters and Glycidyl Esters (GE) in Infant and Adult/Pediatric Nutritional Formula by Gas Chromatography Coupled to Mass Spectrometry Method, First Action 2018.03. J. AOAC Int. 2018, 1-12.

(25) Leigh, J. K.; MacMahon, S. Extraction and Liquid Chromatography-Tandem Mass

(26) Zelinkova, Z.; Giri, A.; Wenzl, T. Assessment of Critical Steps of a GC/MS Based Indirect Analytical Method for the Determination of Fatty Acid Esters of Monochloropropanediols (MCPDEs) and of Glycidol (GEs). Food Control 2017, 77, 65-75. https://doi.org/10.1016/j.foodcont.2017.01.024.

(27) European Commission. Commission Regulation (EU) No 836/2011 of 19 August 2011. Off. J. Eur. Union 2011, L215 (836), 9-16. 
(28) Cheng, W. W.; Liu, G. Q.; Wang, L. Q.; Liu, Z. S. Glycidyl Fatty Acid Esters in Refined Edible Oils: A Review on Formation, Occurrence, Analysis, and Elimination Methods. Compr. Rev. Food Sci. Food Saf. 2017, 16 (2), 263-281. https://doi.org/10.1111/1541-4337.12251.

(29) European Commission. Commission Regulation (EU) 2018/290 of 26 February 2018. Off. J. Eur. Union 2018, L55 (61), 27.

(30) Chinnaswamy, R.; Hanna, M. A. Optimum Extrusion- Cooking Conditions for Maximum Expansion of Corn Starch. J. Food Sci. 1988, 53 (3), 834-836. https://doi.org/10.1111/j.1365-2621.1988.tb08965.x.

(31) Zelinková, Z.; Doležal, M.; Velíšek, J. Occurrence of 3-Chloropropane-1,2-Diol Fatty Acid Esters in Infant and Baby Foods. Eur. Food Res. Technol. 2009, 228 (4), 571578. https://doi.org/10.1007/s00217-008-0965-0.

(32) Rahn, A. K. K.; Yaylayan, V. A. What Do We Know about the Molecular Mechanism of 3-MCPD Ester Formation? Eur. J. Lipid Sci. Technol. 2011, 113 (3), 323-329. https://doi.org/10.1002/ejlt.201000310.

(33) Zhao, Y.; Zhang, Y.; Zhang, Z.; Liu, J.; Wang, Y. L.; Gao, B.; Niu, Y.; Sun, X.; Yu, L. Formation of 3-MCPD Fatty Acid Esters from Monostearoyl Glycerol and the Thermal Stability of 3-MCPD Monoesters. J. Agric. Food Chem. 2016, 64 (46), 8918-8926. https://doi.org/10.1021/acs.jafc.6b04048.

(34) Wöhrlin, F.; Fry, H.; Lahrssen-Wiederholt, M.; Preiß-Weigert, A. Occurrence of Fatty Acid Esters of 3-MCPD, 2-MCPD and Glycidol in Infant Formula. Food Addit. Contam. - Part A Chem. Anal. Control. Expo. Risk Assess. 2015, 32 (11), 1810-1822. https://doi.org/10.1080/19440049.2015.1071497.

(35) Becalski, A.; Zhao, T.; Feng, S.; Lau, B. P. Y. A Pilot Survey of 2- and 3- 

Canadian Market 2012-2013. J. Food Compos. Anal. 2015, 44, 111-114. https://doi.org/10.1016/j.jfca.2015.08.004.

503

(36) Kuhlmann, J. Determination of Bound 2,3-Epoxy-1-Propanol (Glycidol) and Bound Monochloropropanediol (MCPD) in Refined Oils. Eur. J. Lipid Sci. Technol. 2011, 113 (3), 335-344. https://doi.org/10.1002/ejlt.201000313.

(37) Ermacora, A.; Hrncirik, K. A Novel Method for Simultaneous Monitoring of 2-MCPD, 3-MCPD and Glycidyl Esters in Oils and Fats. JAOCS, J. Am. Oil Chem. Soc. 2013, 90 (1), 1-8. https://doi.org/10.1007/s11746-012-2132-9.

(38) Ermacora, A.; Hrncirik, K. Study on the Thermal Degradation of 3-MCPD Esters in Model Systems Simulating Deodorization of Vegetable Oils. Food Chem. 2014, 150, 158-163. https://doi.org/10.1016/j.foodchem.2013.10.063.

(39) Sundhedsstyrelsen; Fødevarestyrelsen; Komiteen for Sundhedsoplysning. Mad til små https://altomkost.dk/fileadmin/user_upload/altomkost.dk/Publikationsdatabase/Pjecer_ plakater_mv/Mad_til_smaa_-Fra_maelk_til_familiens_mad.pdf (accessed Aug 8, 2019).

(40) Sundhedsstyrelsen. Ernæring til spædbørn og småbørn https://www.sst.dk/da/sundhedog-livsstil/ernaering/ /media/2986643F11A44FA18595511799032F85.ashx (accessed Aug 8, 2019). 
Highlights for the manuscript: "Monochloropropanediol and glycidyl esters in infant formula and baby food products on the Danish market: Occurrence and preliminary risk assessment"

- 2- and 3-MCPDEs and GEs were analyzed in Danish infant formula and baby foods

- Most products contained low levels of MCPDEs and GEs

- Highest concentrations of MCPDEs were in baby biscuit and of GEs were in baby puff

- GEs formation might take place during puff production

- Consumption of infant formula does not cause an apparent risk for infants 


\section{Declaration of interests}

$\bigotimes$ The authors declare that they have no known competing financial interests or personal relationships that could have appeared to influence the work reported in this paper.

$\square$ The authors declare the following financial interests/personal relationships which may be considered as potential competing interests:

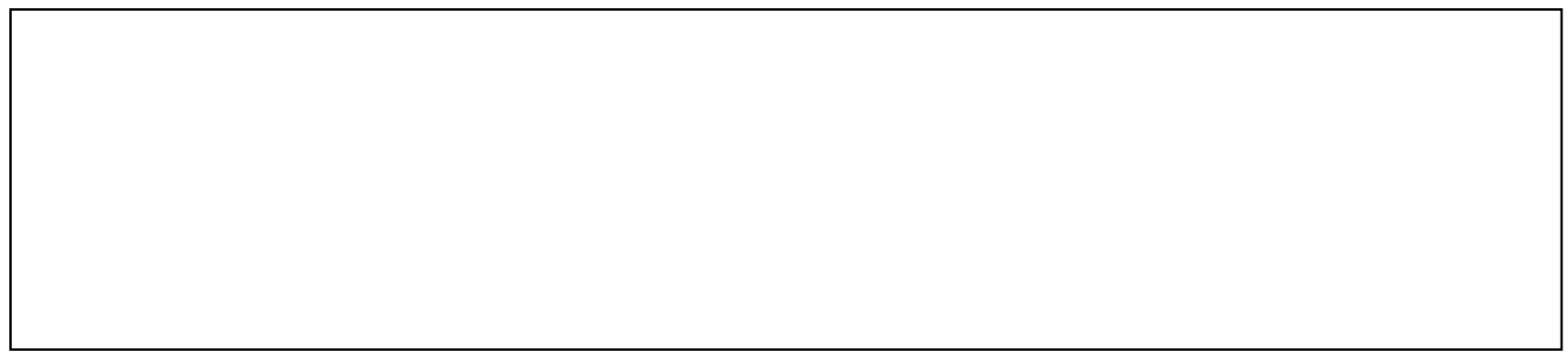


Table 1. Concentrations of 2-MCPDEs, 3-MCPDEs and GEs in infant formula and baby food products purchased in Denmark

\begin{tabular}{|c|c|c|c|c|c|c|c|c|c|}
\hline Item & Sample type & Oil composition ${ }^{*}$ & Brand & $\begin{array}{l}\text { Intended } \\
\text { age of use } \\
\text { (months) }\end{array}$ & $\begin{array}{l}\text { Fat } \\
\text { content } \\
(\%)^{*}\end{array}$ & $\begin{array}{l}\text { 2-MCPDEs } \\
(\mu \mathrm{g} / \mathrm{kg})\end{array}$ & $\begin{array}{l}\text { 3-MCPDEs } \\
(\mu \mathrm{g} / \mathrm{kg})\end{array}$ & $\begin{array}{l}\text { GEs } \\
(\mu \mathrm{g} / \mathrm{kg})\end{array}$ & $\begin{array}{l}\text { Ratio } \\
2-/ 3- \\
\text { MCPDEs } \\
\end{array}$ \\
\hline & Biscuits & & & & & & & & \\
\hline 2 & & palm & $\mathrm{E}$ & 10 & 11.2 & 44.7 & 96.3 & 16.2 & 0.46 \\
\hline 3 & & palm & $\mathrm{E}$ & 10 & 12.9 & 52.8 & 102.6 & 23.9 & 0.51 \\
\hline 4 & & palm, sunflower & $\mathrm{F}$ & 10 & 13.5 & 34.8 & 71.7 & 24.6 & 0.49 \\
\hline 5 & & rapeseed & $\mathrm{D}$ & 6 & 2.7 & 1.2 & 3.2 & 2.2 & 0.37 \\
\hline 6 & & rapeseed & $\mathrm{D}$ & 8 & 2.5 & 1.3 & 3.7 & 1.7 & 0.35 \\
\hline 7 & & rapeseed & $\mathrm{D}$ & 6 & 3 & 2.7 & 6.9 & $<$ LOQ & 0.39 \\
\hline 8 & & rapeseed & $\mathrm{D}$ & 8 & 2.1 & 1.7 & 4.4 & 1.8 & 0.38 \\
\hline 9 & & canola & $\mathrm{D}$ & 8 & 3 & 1.3 & 3.7 & 1.5 & 0.35 \\
\hline 10 & & rapeseed & A & 6 & 2.5 & 1.4 & 3.6 & $<$ LOQ & 0.39 \\
\hline 14 & & rapeseed & A & 6 & 3.2 & 1.8 & 6.0 & $<$ LOQ & 0.31 \\
\hline 15 & & rapeseed & A & 6 & 3 & 1.3 & 3.7 & 1.5 & 0.35 \\
\hline 16 & & rapeseed & A & 6 & 2.5 & $<\mathrm{LOQ}$ & 4.2 & $<$ LOQ & NA \\
\hline 17 & & rapeseed & A & 6 & 3 & 1.5 & 5.0 & 1.3 & 0.31 \\
\hline 18 & & rapeseed & A & 6 & 3 & $<\mathrm{LOQ}$ & 3.1 & 1.9 & NA \\
\hline 19 & & rapeseed & $\mathrm{D}$ & 8 & 2.8 & 3.8 & 9.9 & 2.4 & 0.39 \\
\hline 20 & & rapeseed & $\mathrm{D}$ & 6 & 0.6 & $<\mathrm{LOQ}$ & $<\mathrm{LOQ}$ & $<\mathrm{LOQ}$ & NA \\
\hline 21 & & rapeseed & $\mathrm{D}$ & 6 & 0.6 & $<\mathrm{LOQ}$ & 2.2 & 1.5 & NA \\
\hline 22 & & canola & $\mathrm{F}$ & 6 & 0.5 & $<\mathrm{LOQ}$ & $<\mathrm{LOQ}$ & $<$ LOQ & $\mathrm{NA}$ \\
\hline
\end{tabular}




\section{canola \\ rapeseed \\ rapeseed}

Cereal based

Liquid formula

rapeseed, sunflower

rapeseed, sunflower

rapeseed, sunflower

rapeseed, sunflower

no added oil

rapeseed, sunflower

canola, sunflower

palm, sunflower, canola puree powder

$\begin{array}{ll}\text { F } & 6 \\ \text { A } & 6\end{array}$

A 6

A 6

A 8

A 6

A 6

A 6

A 4

A 6

D 6

palm, rapeseed, coconut,

sunflower

palm, sunflower, rapeseed,

coconut, fish

palm, sunflower, rapeseed,

coconut, fish

palm, sunflower, rapeseed,

coconut, fish

palm, rapeseed, soybean,

coconut

palm, rapeseed, soybean,

coconut

Powder

formula

A $\quad 0$

A 6

C $\quad 0$

C 6

B

B

0

$20-7.9$

$20 \quad 9.2$

20

$3.1 \quad 3.7$




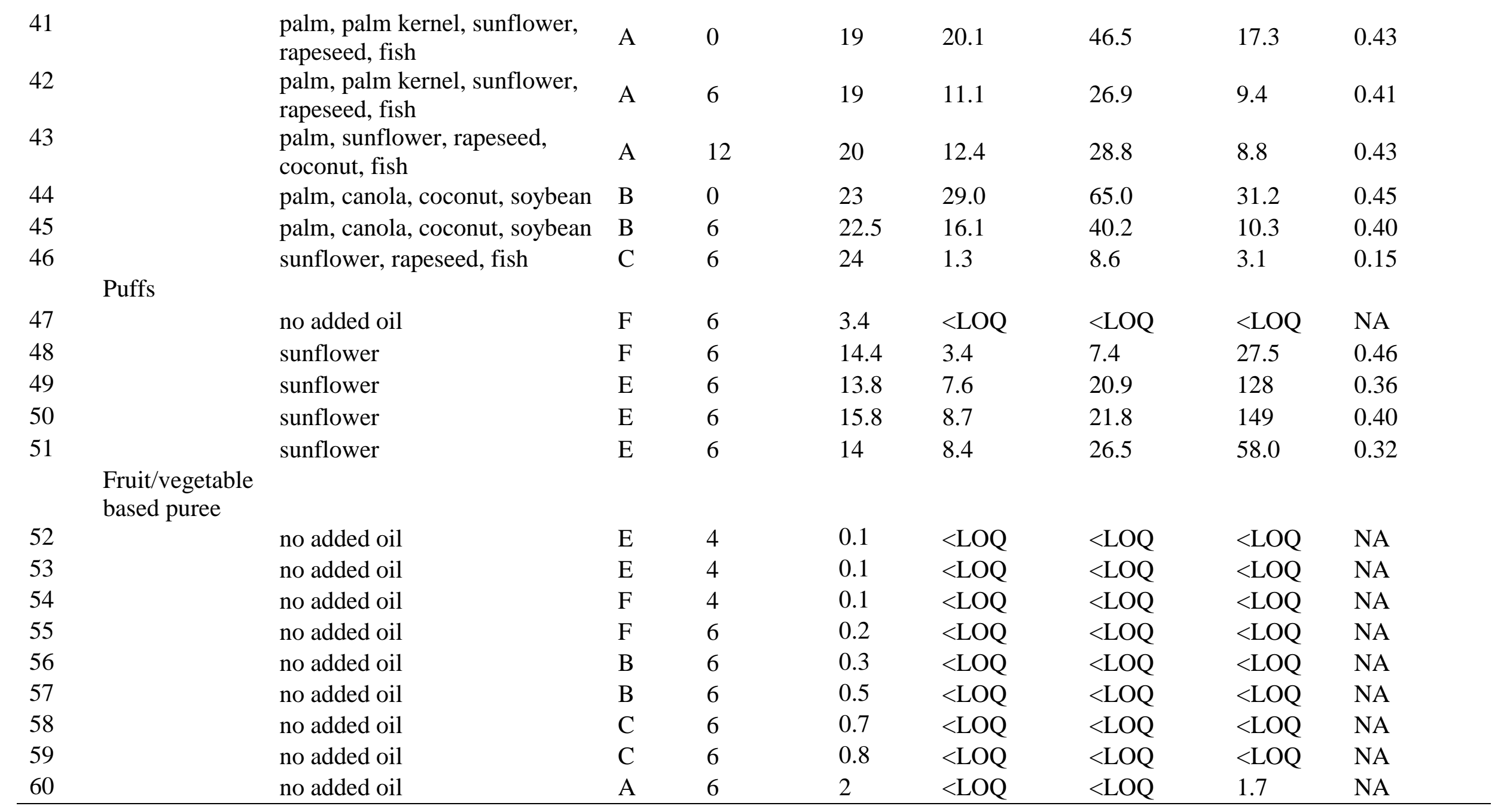

*: information specified on the labels 
Table 2. Validation results, LODs, and LOQs for 2-MCPDEs, 3-MCPDEs and GEs in oil, infant formula, and baby food

\begin{tabular}{|c|c|c|c|c|c|c|c|}
\hline Matrices & Parameters & \multicolumn{2}{|c|}{ 2-MCPDEs } & \multicolumn{2}{|c|}{ 3-MCPDEs } & \multicolumn{2}{|c|}{ GEs } \\
\hline \multirow{6}{*}{ Oil } & Spike level $(\mu \mathrm{g} / \mathrm{kg})^{*}$ & 98.8 & 988 & 98.8 & 988 & 117 & 1174 \\
\hline & $\mathrm{R}(\%)$ & 93 & 101 & 94 & 94 & 91 & 84 \\
\hline & $\mathrm{CV}_{\mathrm{LR}}(\%)$ & 2.0 & 1.3 & 2.8 & 1.8 & 3.4 & 2.9 \\
\hline & $\mathrm{CV}_{\mathrm{DR}}(\%)$ & 2.0 & 1.2 & 2.8 & 1.8 & 3.4 & 2.9 \\
\hline & $L O D(\mu g / k g)^{*}$ & \multicolumn{2}{|c|}{2.3} & \multicolumn{2}{|c|}{3.2} & \multicolumn{2}{|c|}{1.9} \\
\hline & $L O Q(\mu g / k g)^{*}$ & \multicolumn{2}{|c|}{7.6} & \multicolumn{2}{|c|}{10.7} & \multicolumn{2}{|c|}{6.2} \\
\hline \multirow{6}{*}{$\begin{array}{l}\text { Infant } \\
\text { formula }\end{array}$} & Spike level $(\mu \mathrm{g} / \mathrm{kg})^{*}$ & 3.3 & 33 & 3.3 & 33 & 3.9 & 39.1 \\
\hline & $\mathrm{R}(\%)$ & 99 & 99 & 95 & 95 & 94 & 95 \\
\hline & $\mathrm{CV}_{\mathrm{LR}}(\%)$ & 1.2 & 1.3 & 1.1 & 1.4 & 1.1 & 2.2 \\
\hline & $\mathrm{CV}_{\mathrm{DR}}(\%)$ & 1.2 & 1.3 & 1.1 & 1.4 & 2.1 & 2.4 \\
\hline & $L O D(\mu g / k g)^{*}$ & \multicolumn{2}{|c|}{0.4} & \multicolumn{2}{|c|}{0.3} & \multicolumn{2}{|c|}{0.1} \\
\hline & $L O Q(\mu g / k g)^{*}$ & \multicolumn{2}{|c|}{1.2} & \multicolumn{2}{|c|}{1.0} & \multicolumn{2}{|c|}{0.5} \\
\hline \multirow{6}{*}{$\begin{array}{l}\text { Baby } \\
\text { food }\end{array}$} & Spike level $(\mu \mathrm{g} / \mathrm{kg})^{*}$ & 3.3 & 33 & 3.3 & 33 & 3.9 & 39.1 \\
\hline & $\mathrm{R}(\%)$ & 106 & 100 & 93 & 91 & 98 & 99 \\
\hline & $\mathrm{CV}_{\mathrm{LR}}(\%)$ & 7.8 & 3.3 & 3.0 & 1.9 & 5.9 & 2.4 \\
\hline & $\mathrm{CV}_{\mathrm{DR}}(\%)$ & 2.7 & 2.3 & 3.0 & 1.8 & 5.9 & 1.3 \\
\hline & $L O D(\mu g / k g)^{*}$ & \multicolumn{2}{|c|}{0.3} & \multicolumn{2}{|c|}{0.6} & \multicolumn{2}{|c|}{0.4} \\
\hline & $L O Q(\mu \mathrm{g} / \mathrm{kg})^{*}$ & \multicolumn{2}{|c|}{1} & \multicolumn{2}{|c|}{2} & \multicolumn{2}{|c|}{1.2} \\
\hline
\end{tabular}

$\mathrm{R}$ : recovery; $\mathrm{CV}_{\mathrm{LR}}$ : coefficient of variation under intra-lab reproducibility; $\mathrm{CV}_{\mathrm{DR}}$ : coefficient of variation under intra-day repeatability

*: free form equivalents 
Table 3. Concentrations of MCPDEs and GEs $(\mu \mathrm{g} / \mathrm{kg})$ in infant formula from this study and comparison with other studies

\begin{tabular}{|c|c|c|c|c|c|c|c|c|c|}
\hline Region & $\begin{array}{l}\text { Sampling } \\
\text { year }\end{array}$ & Sample type & \multicolumn{2}{|c|}{ 2-MCPDEs } & \multicolumn{2}{|c|}{ 3-MCPDEs } & \multicolumn{2}{|l|}{ GEs } & Reference \\
\hline Czech & 2006 & Powder & & & $62-588$ & $\begin{array}{l}312 \\
\text { (median) }\end{array}$ & & & $\begin{array}{l}\text { Zelinková et al., } \\
2009\end{array}$ \\
\hline Germany $^{*}$ & 2013 & Powder & $24-85$ & 48.5 & $67-177$ & 109 & $40-213$ & 93 & $\begin{array}{l}\text { Wöhrlin et al., } \\
2015\end{array}$ \\
\hline Europe & 2012-2013 & Powder & & 44 & & 108 & & 87 & $\begin{array}{l}\text { EFSA CONTAM } \\
\text { Panel, } 2016\end{array}$ \\
\hline Brazil & 2015 & Powder & & 150 & ND-600 & 220 & ND-750 & & $\begin{array}{l}\text { Arisseto et al., } \\
2017\end{array}$ \\
\hline China & $\begin{array}{l}\text { NA, before } \\
2015\end{array}$ & Powder & ND-52 & 41 & ND-316 & 185 & & & Wang et al., 2016 \\
\hline Denmark & 2019 & Powder & $1.3-29$ & 15 & $8.6-65$ & 36 & $3.1-31$ & 13.4 & This study \\
\hline
\end{tabular}

Data was calculated based on fat content declared on packaging

** Normalized by conversion of concentrations in fat basis into product basis assuming $3.5 \%$ fat in liquid form 
Table 4. Estimated intake of MCPDEs and GEs in infant formula from this study and comparison with other studies

\begin{tabular}{lllllll}
\hline Region & $\begin{array}{l}\text { Sampling } \\
\text { year }\end{array}$ & $\begin{array}{l}\text { Age group } \\
(\mathrm{months})\end{array}$ & $\begin{array}{l}\text { 2-MCPDEs intake* } \\
(\mu \mathrm{g} / \mathrm{kg} \text { b.w/day) }\end{array}$ & $\begin{array}{l}\text { 3-MCPDEs intake* } \\
(\mu \mathrm{g} / \mathrm{kg} \text { b.w/day) }\end{array}$ & $\begin{array}{l}\text { GEs intake* } \\
(\mu \mathrm{g} / \mathrm{kg} \text { b.w/day) }\end{array}$ & Reference \\
\hline Europe & $2012-2013$ & $1-4$ & 1 & 2.4 & 1.9 & EFSA CONTAM Panel, 2016 \\
& & & & 10 & 2 & Spungen et al., 2018 \\
U.S.A & $2013-2016$ & $0-1$ & $2-3$ & 8 & 2 & Arisseto et al., 2017 \\
& & $5-6$ & & 7 & 2 & This study \\
Brazil & 2015 & $0-5$ & & 2.49 & 0.49 & 0.15 \\
Denmark & 2019 & $0-1$ & 0.3 & 0.75 & & \\
\hline
\end{tabular}

*Data was calculated using mean concentrations of the contaminants 


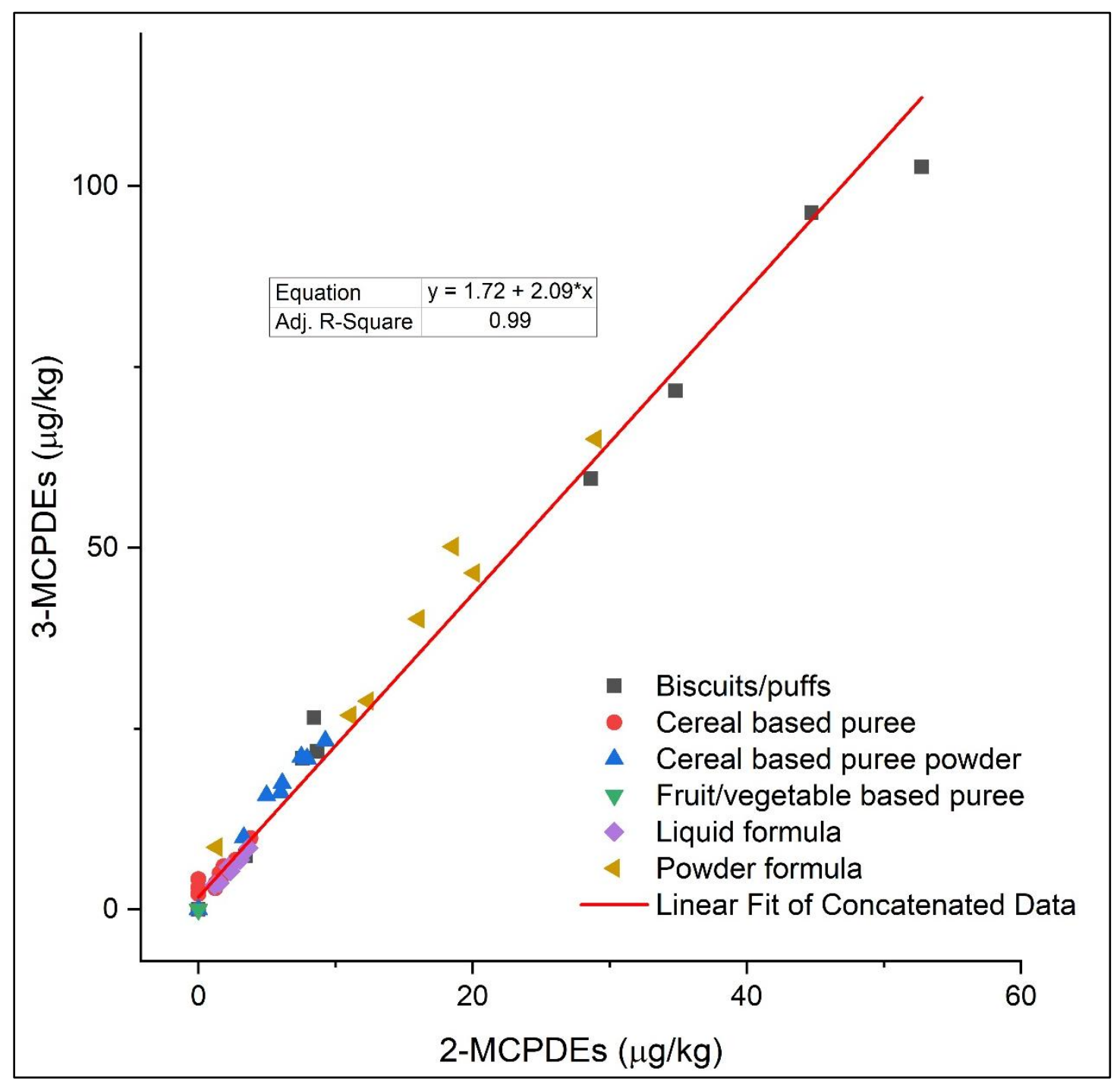

Figure 1. Scatter plot and linear regression analysis between the concentrations of 2-MCPDEs and 3-MCPDEs in infant formula and baby foods 

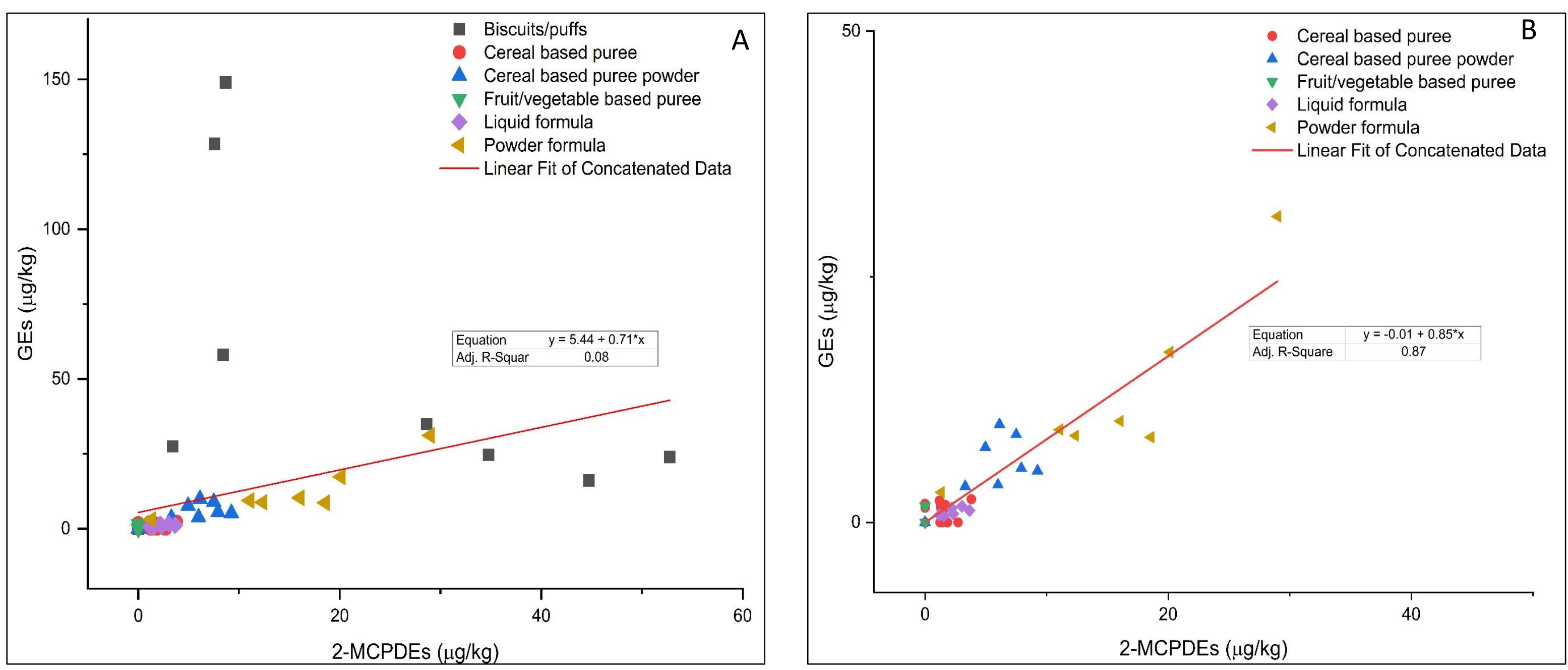

Figure 2. Scatter plot and linear regression analysis between the concentrations of 2-MCPDEs and GEs in infant formula and baby foods with (A) or without (B) biscuit and puff product 

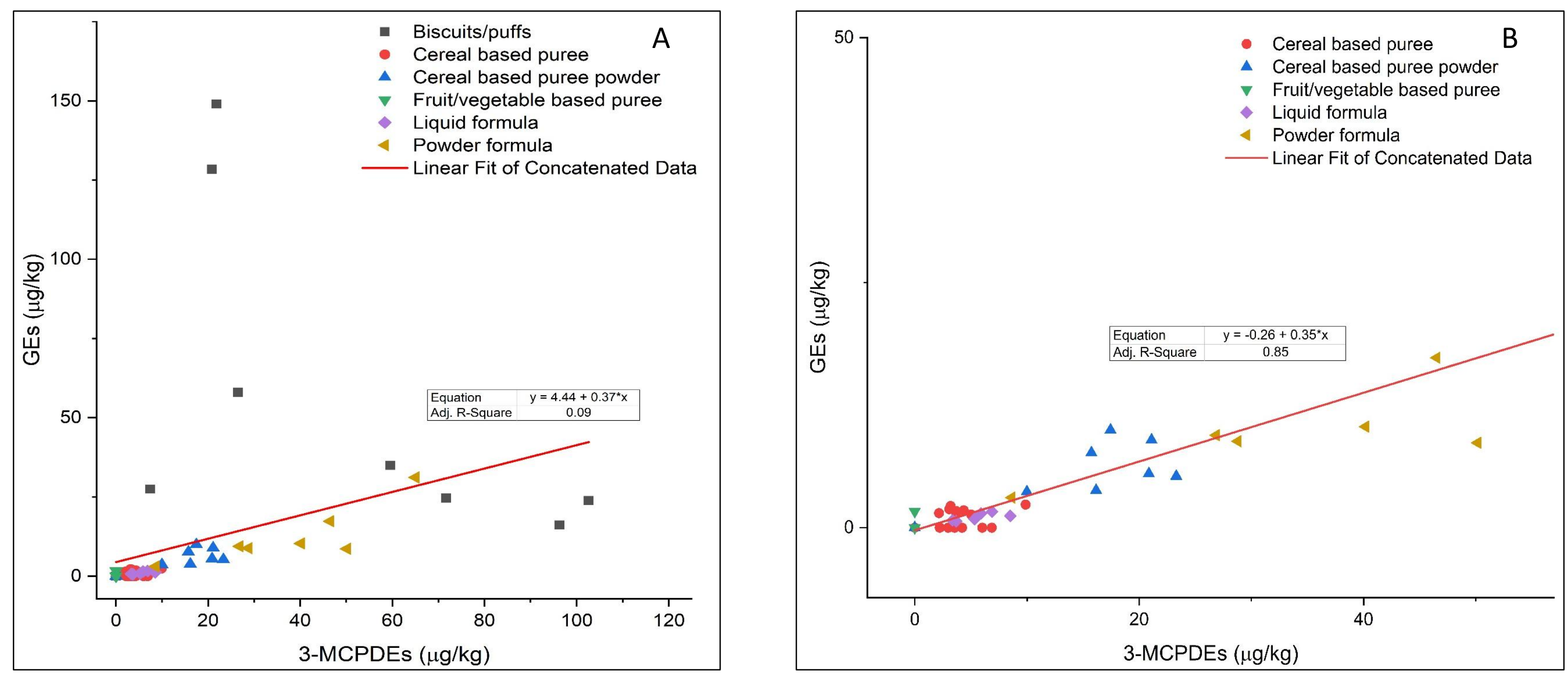

Figure 3. Scatter plot and linear regression analysis between the concentrations of 3-MCPDEs and GEs in infant formula and baby foods with (A) or without (B) biscuit and puff product 
Table S.1. Selected reaction monitoring parameters for the analysis of 2-MCPDEs, 3MCPDEs and GEs by GC-MS/MS in positive EI mode.

\begin{tabular}{lllcc}
\hline Compound & Analysis form & Transition & $\begin{array}{c}\text { Collision } \\
\text { Energy }\end{array}$ & Dwell time (sec) \\
\hline \multirow{2}{*}{ 3-MCPDEs } & 3-MCPD-PBA & $\mathbf{1 9 6} \rightarrow \mathbf{1 4 7}$ & 8 & 0.2 \\
\cline { 3 - 5 } & & $198 \rightarrow 147$ & 8 & 0.2 \\
\hline PP-3-MCPD-d5 & 3-MCPD-d5-PBA & $\mathbf{2 0 1} \rightarrow \mathbf{1 5 0}$ & 8 & 0.2 \\
\cline { 3 - 5 } & & $150 \rightarrow 93$ & 20 & 0.2 \\
\hline 2-MCPDEs & 2-MCPD-PBA & $\mathbf{1 9 6} \rightarrow \mathbf{1 0 4}$ & 16 & 0.2 \\
\cline { 3 - 5 } & & $198 \rightarrow 104$ & 16 & 0.2 \\
\hline PP-2-MCPD-d5 & 2-MCPD-d5-PBA & $201 \rightarrow 104$ & 20 & 0.2 \\
\cline { 3 - 5 } & & $\mathbf{2 0 1} \rightarrow \mathbf{1 0 7}$ & 12 & 0.2 \\
\hline GEs & & $\mathbf{2 4 0} \rightarrow \mathbf{1 4 7}$ & 8 & 0.2 \\
\hline Gly-P-d5 & 3-MBPD-PBA & $\mathbf{2 4 2} \rightarrow 147$ & 8 & 0.2 \\
\cline { 3 - 5 } & & $\mathbf{2 4 7} \rightarrow \mathbf{1 5 0}$ & 8 & 0.2 \\
\hline
\end{tabular}

Transitions in bold are quantifying transitions 
Table S.2. Concentrations of 3-MCPDEs and GEs in FAPAS T2646QC vegetable oil sample by duplicated analysis on various days

\begin{tabular}{|c|c|c|c|c|c|c|c|c|c|c|c|c|}
\hline & $\begin{array}{l}\text { Assigned } \\
\text { value }^{*}\end{array}$ & $\begin{array}{l}\text { Range } \\
\text { for }|\mathrm{z}|^{* *} \\
\leq 2\end{array}$ & $\begin{array}{l}\text { Day } \\
1\end{array}$ & $\begin{array}{l}\text { Day } \\
1\end{array}$ & $\begin{array}{l}\text { Day } \\
2\end{array}$ & $\begin{array}{l}\text { Day } \\
2\end{array}$ & $\begin{array}{l}\text { Day } \\
3\end{array}$ & $\begin{array}{l}\text { Day } \\
3\end{array}$ & $\begin{array}{l}\text { Day } \\
4\end{array}$ & $\begin{array}{l}\text { Day } \\
4\end{array}$ & $\begin{array}{l}\text { Day } \\
5\end{array}$ & $\begin{array}{l}\text { Day } \\
5\end{array}$ \\
\hline $\begin{array}{l}\text { 3- } \\
\text { MCPDEs* }\end{array}$ & 586 & $\begin{array}{l}325- \\
821\end{array}$ & 533 & 530 & 524 & 539 & 539 & 600 & 502 & 556 & 495 & 490 \\
\hline GEs $^{*}$ & 255 & $\begin{array}{l}153- \\
357\end{array}$ & 219 & 213 & 198 & 215 & 218 & 229 & 225 & 249 & 210 & 215 \\
\hline
\end{tabular}


Table S.3. Spearman's rank correlation coefficients between fat content and the levels of MCPDEs and GEs in infant formula and baby food products $(p<0.001$ in all cases)

\begin{tabular}{llll}
\hline & 2-MCPDEs & 3-MCPDEs & GEs \\
\hline Fat content & 0.863 & 0.887 & 0.815 \\
2-MCPDEs & & 0.972 & 0.866 \\
3-MCPDEs & & & 0.878 \\
& & & \\
\hline
\end{tabular}

